\title{
Pengelolaan Ekosistem Gambut Pasca Kebakaran Lahan Gambut di Provinsi Kalimantan Tengah
}

\author{
Sari Marlina \\ Program Studi Teknik Lingkungan Universitas Muhammadiyah Palangkaraya \\ email: sarimarlina9898@gmail.com
}

\begin{abstract}
ABSTRAK. Ekosistem gambut Indonesia, khususnya Kalimantan Tengah telah mengalami kerusakan yang masif akibat pemanfaatan yang melebihi daya dukung dan daya tampungnya, serta adanya kebakaran lahan. Undang-Undang Nomor 32 Tahun 2009 tentang Perlindungan dan Pengelolaan Lingkungan Hidup menyatakan bahwa ekosistem gambut merupakan bagian penting dari lingkungan hidup yang harus dilindungi dan dikelola dengan baik.Oleh karena itu, pasca kebakaran lahan gambut di Kalimantan Tengah, perlu adanya pengelolaan ekosistem gambut tersebut. Hal-hal yang perlu dilakukan adalah adanya penataan ulang ekosistem gambut, program pencegahan kerusakan ekosistem gambut, pemulihan, rehabilitasi dan restorasi ekosistem gambut. Perlu banyak peran aktif dari berbagai pihak, baik pemerintah maupun masyarakat dalam rangka pengelolaan lahan gambut agar tetap terjaga.
\end{abstract}

Kata kunci : kebakaran, ekosistem, gambut

\section{PENDAHULUAN}

Kerusakan fungsi ekosistem gambut terjadi akibat dari pengelolaan lahan yang salah dengan pemilihan komoditas bisnis yang tidak sesuai dengan karakteristik lahan gambut. Hal ini diperparah dengan pengurasan air gambut yang berakibat kekeringan (kering tak balik) pada gambutnya itu sendiri yang saat ini sebagai pemicu kebakaran. Fakta dilapangan menunjukkan kebakaran yang terjadi hampir setiap tahun dengan luasan yang selalu bertambah merupakan kenyataan bahwa gambut tidak lagi dalam kondisi alaminya atau sudah mengalami kerusakan.

\section{PEMBAHASAN}

\section{Penataan Ulang Ekosistem Gambut}

- Prinsipnya penataan ulang dilakukan dalam Kesatuan Hidrologis Gambut,

- Satuan hidrologis agar dijadikan dasar peruntukan, zona konservasi (kubah) zona penyangga - zona pemanfaatan,

- Restorasi tata air (rewetting) ekosistem gambut

- Rehabilitasi vegetasi ekosistem gambut

- Menata ulang Pemanfaatan Lahan Gambut di kawasan Budi daya

- Mempertahankan kubah gambut, terhindar dari banjir dan kekeringan dan kebakaran .

- Inputan secukupnya agar tidak dimanfaatkan oleh kegiatan jasad renik yang dapat mempercepat laju emisi. 
Gambar 1 berikut menunjukkan daerah sebaran lahan gambut dan kejadian kebakaran di Kalimantan Tengah tahun 2015.
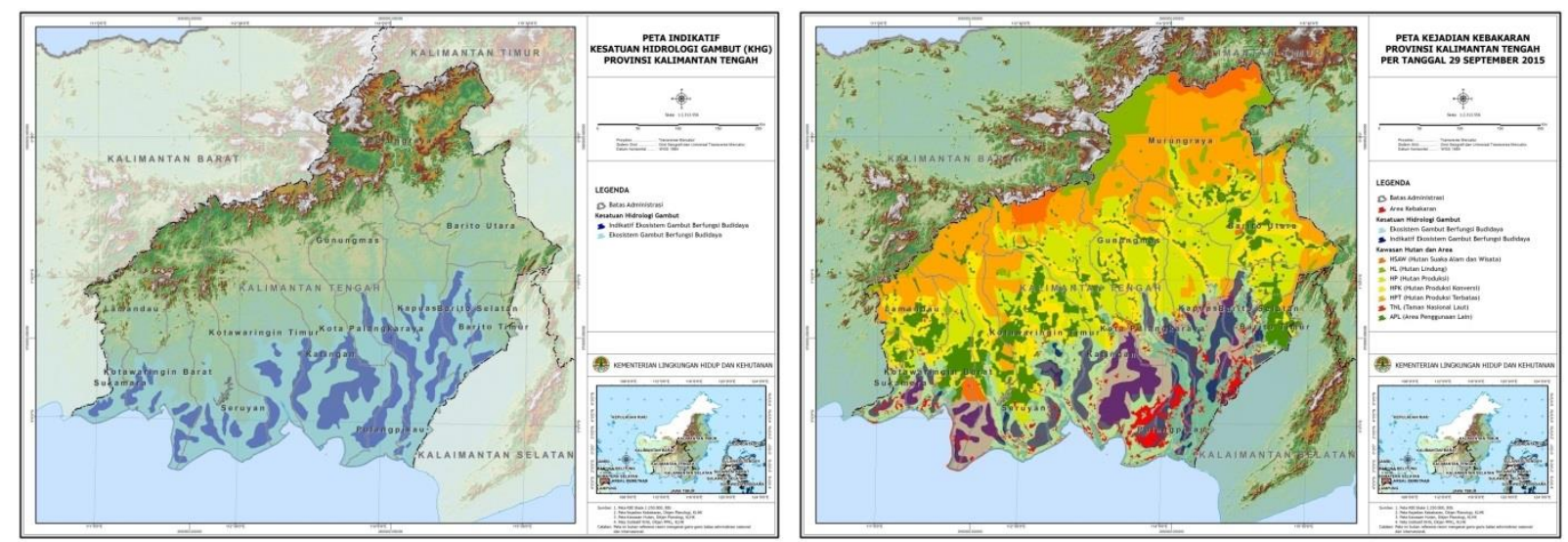

Gambar 1. Peta indikatif Kesatuan Hidrologi Gambut (KHG) (kiri) dan peta kejadian kebakaran Provinsi Kalimantan Tengah per tanggal 29 September 2015

Berdasarkan Gambar 1 tersebut, luasan kejadian kebakaran pada kesatuan hidrologis gambut Provinsi Kalimantan Tengah dapat dilihat pada Tabel 1.

Tabel 1. Luasan (Hektar) Kejadian Kebakaran Per Tanggal 29 September 2015 pada Kesatuan Hidrologis Gambut Provinsi Kalimantan Tengah

\begin{tabular}{|c|c|c|c|c|c|c|c|c|c|c|c|c|c|}
\hline \multirow{2}{*}{$\begin{array}{l}\text { Administrasi } \\
\text { (Kabupaten/ } \\
\text { Kecamatan) }\end{array}$} & \multicolumn{6}{|c|}{ Ekosistem Gambut Berfungsi Budidaya } & \multicolumn{6}{|c|}{ Indikatif Ekosistem Gambut Berfungsi Lindung } & \multirow[t]{2}{*}{ TOTAL } \\
\hline & APL & HL & HP & HPK & HPT & HSAW & APL & HL & HP & HPK & HPT & HSAW & \\
\hline Barito Selatan & $13.087,5$ & $5.939,5$ & $2.647,6$ & $1.445,7$ & 545,4 & $5.149,5$ & $4.936,3$ & 157,2 & 260,4 & $1.278,0$ & 143,8 & 601,7 & 36.192, \\
\hline Dusun Hilir & $6.778,6$ & $3.124,8$ & 579,0 & 263,8 & & $4.968,8$ & $4.528,7$ & & & 416,9 & & 418,5 & 21.079 , \\
\hline Dusun Selatan & 501,5 & 875,8 & & 813,3 & 545,4 & $+\quad 180,7$ & 266,7 & 132,2 & 203,8 & 860,5 & 143,8 & 175,1 & 4.698 \\
\hline Jenamas & $5.461,1$ & & $2.068,6$ & 157,3 & & & & & 56,6 & & & & $7.743,5$ \\
\hline Karaukuala & 346,4 & $1.938,9$ & & 211,4 & & & 140,8 & 25,0 & & 0,6 & & 8,2 & $2.671,1$ \\
\hline Barito Timur & $2.272,4$ & & $2.591,5$ & $4.414,5$ & & & 318,4 & & 344,7 & 205,0 & & & $10.146,7$ \\
\hline Dusun Tengah & 328,2 & & & 196,8 & & & 0,4 & & & & & & 525,5 \\
\hline Dusun Timur & $1.098,0$ & & $1.479,0$ & $1.598,2$ & & & 318,0 & & 344,7 & 174,2 & & & $5.012,0$ \\
\hline Pematangkarau & 846,2 & & $1.112,6$ & $2.619,5$ & & & & & & 30,9 & & & $4.609,2$ \\
\hline Kapuas & $31.932,2$ & $9.413,6$ & $1.545,2$ & $1.330,9$ & 255,2 & $4.376,8$ & $16.344,5$ & $6.194,7$ & 413,2 & 417,0 & 696,9 & 256,1 & $\mathbf{7 3 . 1 7 6 , 3}$ \\
\hline Basarang & 0,1 & 29,1 & & & & & 314,4 & 883,1 & & & 252,9 & & $1.479,7$ \\
\hline Kapuas Barat & $4.585,2$ & 60,5 & & & 203,5 & & 582,2 & 267,5 & & & 324,6 & & $6.023,4$ \\
\hline Kapuas Hilir & 57,8 & & & & & & & & & & & & 57, \\
\hline Kapuas Timur & $1.954,8$ & & & & & & & & & & & & 1.954 \\
\hline Kapuaskuala & $2.871,7$ & & & & & & 12,3 & & & & & & $2.884,0$ \\
\hline murung & $14.970,8$ & & & & & & $14.420,5$ & & & & & & $29.391,3$ \\
\hline Mantangai & $6.987,7$ & $9.324,0$ & $1.545,2$ & & & $2.788,1$ & 703,2 & $5.044,1$ & 333,2 & & & 168,4 & $26.893,9$ \\
\hline Selat & 366,8 & & & & 51,7 & & 311,9 & & & & 119,4 & & 849,8 \\
\hline Timpah & 137,3 & & & $1.330,9$ & & $1.588,7$ & & & 80,0 & 417,0 & & 87,7 & $3.641,6$ \\
\hline Katingan & $16.023,6$ & $1.443,8$ & $26.327,4$ & $14.955,9$ & & $20.142,2$ & 152,9 & $10.265,6$ & $4.767,41$ & $1.056,5$ & & $8.985,1$ & $104.120,3$ \\
\hline Kamipang & 68,3 & & & $2.304,1$ & & 329,3 & & & & 54,0 & & 105,2 & $2.860,9$ \\
\hline Katingan Hilir & 203,7 & & & 43,6 & & & & & & & & & 247,3 \\
\hline Kating & $15.315,6$ & $1.443,8$ & $25.397,2$ & $6.452,6$ & & $16.285,5$ & 152,9 & $10.265,6$ & $4.767,4$ & 866,3 & & $8.848,5$ & $89.795,3$ \\
\hline Mend & 331,9 & & 930,2 & $4.743,5$ & & $3.488,7$ & & & & 136,2 & & 31,3 & $9.661,9$ \\
\hline Tasikpayawan & 104,1 & & & $1.412,0$ & & 38,7 & & & & & & & $1.554,8$ \\
\hline Kota Palangkaraya & $1.680,1$ & 855,0 & & $4.512,6$ & & 133,1 & & & & & & 329,3 & $7.510,0$ \\
\hline Bukitbatu & 2,0 & & & 753,5 & & 70,8 & & & & & & & 826,2 \\
\hline Jekanraya & 105,2 & & & $3.328,0$ & & 62,3 & & & & & & & $3.495,4$ \\
\hline Pahandut & 486,0 & 4,2 & & 203,1 & & & & & & & & & 693,2 \\
\hline Sebangau & $1.086,9$ & 850,8 & & 228,0 & & & & & & & & 329,3 & 2.495 \\
\hline $\begin{array}{l}\text { Kotawaringin } \\
\text { Barat }\end{array}$ & $2.501,2$ & & $3.640,3$ & $5.812,3$ & & $1.963,6$ & 631,3 & & $1.073,2$ & 219,8 & & $5.451,7$ & 21.293, \\
\hline Arut Selatan & $1.738,5$ & & 497,5 & $5.202,7$ & & 226,0 & 18,2 & & 220,2 & 79,1 & & 221,3 & 8.203 \\
\hline Kotawaringinlama & 117,0 & & 115,6 & 351,9 & & 16,4 & 4,0 & & 55,2 & 140,7 & & & 800 \\
\hline Kumai & 645,7 & & $3.027,2$ & 257,7 & & $1.721,2$ & 609,1 & & 797,8 & & & $5.230,4$ & 12.289, \\
\hline
\end{tabular}


Tabel 1. Lanjutan

\begin{tabular}{|c|c|c|c|c|c|c|c|c|c|c|c|c|c|}
\hline \multirow{2}{*}{$\begin{array}{l}\text { Administrasi } \\
\text { (Kabupaten/ } \\
\text { Kecamatan) }\end{array}$} & \multicolumn{6}{|c|}{ Ekosistem Gambut Berfungsi Budidaya } & \multicolumn{6}{|c|}{ Indikatif Ekosistem Gambut Berfungsi Lindung } & \multirow[t]{2}{*}{ TOTAL } \\
\hline & APL & HL & HP & HPK & HPT & HSAW & APL & HL & HP & HPK & HPT & HSAW & \\
\hline $\begin{array}{l}\text { Kotawaringin } \\
\text { Timur }\end{array}$ & 755,9 & & $9.630,5$ & $3.729,4$ & & & $1.866,7$ & & $4.406,91$ & $1.358,9$ & & & $21.748,2$ \\
\hline Baamang & 15,1 & & & 23,1 & & & 284,0 & & 135,2 & 305,4 & & & 762,8 \\
\hline Cempaga & & & 484,7 & 150,3 & & & & & & & & & 635,1 \\
\hline Cempaga Hulu & & & 191,0 & & & & & & & & & & 191,0 \\
\hline Kotabesi & 351,9 & & 61,0 & $1.171,6$ & & & 134,0 & & 427,1 & 1,1 & & & $2.146,8$ \\
\hline $\begin{array}{l}\text { Mentawa } \\
\text { Ketapang }\end{array}$ & & & 666,1 & 12,0 & & & $1.442,7$ & & 183,5 & 317,4 & & & $2.621,8$ \\
\hline $\begin{array}{l}\text { Mentaya } \\
\text { Selatan }\end{array}$ & & & 269,5 & & & & 5,9 & & $1.546,5$ & 729,3 & & & $2.551,2$ \\
\hline $\begin{array}{l}\text { Mentaya hil } \\
\text { Utara }\end{array}$ & 191,7 & & 372,1 & $1.070,8$ & & & & & 184,7 & 5,6 & & & $1.824,8$ \\
\hline Mentaya hulu & & & & 54,3 & & & & & & & & & 54,3 \\
\hline Parenggean & & & & 137,7 & & & & & & & & & 137,7 \\
\hline Pulauhanaut & 22,8 & & $3.562,8$ & 456,5 & & & & & & & & & $4.042,1$ \\
\hline Saranau & 61,7 & & 967,2 & 652,8 & & & & & 15,5 & & & & $1.697,2$ \\
\hline Teluksampit & 112,6 & & $3.056,0$ & 0,3 & & & & & $1.914,4$ & & & & $5.083,4$ \\
\hline $\begin{array}{l}\text { Lamandau } \\
\text { Bulik }\end{array}$ & & & & $\begin{array}{l}\mathbf{5 9 , 9} \\
59,9\end{array}$ & & & & & & & & & $\begin{array}{l}\mathbf{5 9 , 9} \\
59,9\end{array}$ \\
\hline Pulangpisau & $11.191,2$ & $3.661,5$ & $12.169,8$ & 12,4 & 314,9 & $1.482,0$ & $4.056,7$ & $38.481,8$ & $7.148,8$ & & 610,7 & $4.835,6$ & $83.965,3$ \\
\hline Jabirenraya & $1.045,3$ & 888,2 & 93,2 & & & 5,6 & $1.169,1$ & $7.469,0$ & $1.390,5$ & & & & $12.061,0$ \\
\hline Kahayan Hilir & $2.936,3$ & 473,7 & $1.772,2$ & & & & $2.454,8$ & $10.554,5$ & $2.436,5$ & & & & $20.628,1$ \\
\hline Maliku & $4.561,3$ & 128,1 & 615,3 & & 314,9 & & 176,3 & $2.519,3$ & 702,8 & & 475,9 & & $9.493,9$ \\
\hline Mantangai & 24,6 & $1.912,6$ & $8.799,7$ & & & & 81,5 & $13.025,1$ & 455,1 & & & $4.805,6$ & $29.104,2$ \\
\hline Pandihbatu & $2.111,8$ & & 742,9 & & & & 174,9 & $4.900,3$ & $2.163,9$ & & 134,8 & & $10.228,6$ \\
\hline Sebangaukuala & 511,8 & 258,8 & 146,5 & 12,4 & & $1.476,4$ & & 13,6 & & & & 30,0 & $2.449,5$ \\
\hline Seruyan & $2.726,8$ & & $8.909,9$ & $7.684,4$ & & $2.114,4$ & 401,6 & & $1.280,2$ & 329,6 & & $1.767,3$ & $25.214,4$ \\
\hline Danausembuluh & & & & 25,9 & & 108,1 & & & & & & & 134,0 \\
\hline Hanau & 19,2 & & & 96,4 & & & & & & & & & 115,5 \\
\hline Seruyan Hilir & $2.707,7$ & & $8.909,9$ & $7.562,1$ & & $2.006,3$ & 401,6 & & $1.280,2$ & 329,6 & & $1.767,3$ & $24.964,8$ \\
\hline Sukamara & $2.174,9$ & & $7.820,7$ & $1.807,9$ & 149,3 & 978,3 & 12,1 & & $3.546,7$ & 204,9 & $1.928,6$ & 749,3 & $19.372,8$ \\
\hline Jelai & $1.744,3$ & & 421,8 & 777,3 & & & & & $1.666,6$ & & $1.020,9$ & & $5.630,9$ \\
\hline Pantailuncin & 163,0 & & $4.037,5$ & 461,0 & 149,3 & 224,6 & & & 0,4 & & 203,3 & & $5.239,3$ \\
\hline Sukamara & 267,6 & & $3.361,3$ & 569,6 & & 753,7 & 12,1 & & $1.879,7$ & 204,9 & 704,3 & 749,3 & $8.502,6$ \\
\hline Grand Total & $84.345,82$ & $21.313,3$ & $75.283,04$ & $45.765,8$ & $1.264,93$ & $36.339,9$ & $28.720,6$ & $55.099,3$ & $23.241,55$ & $5.069,7$ & $\mathbf{3 . 3 8 0 , 0}$ & $22.976,1$ & 402.799,7 \\
\hline $\begin{array}{ll}\text { 1. Peta } \\
\text { 2. Peta } \\
\text { 3. Peta } \\
\text { 4. Peta }\end{array}$ & $\begin{array}{l}\text { ata : } \\
\text { BI skala } \\
\text { ejadian } \\
\text { awasan } \\
\text { dikatif } \mathrm{K}\end{array}$ & Kebaka & $\begin{array}{l}\text { Ditjend. } \\
\text { Ditjend P }\end{array}$ & $\begin{array}{l}\text { jend. P } \\
\text {. Planol } \\
\text { PPKL, K }\end{array}$ & $\begin{array}{l}\text { anologi } \\
\text { ogi KL } \\
\text { SLHK. }\end{array}$ & $\begin{array}{l}\mathrm{KLH} \\
\mathrm{HK} .\end{array}$ & & & & & & & \\
\hline
\end{tabular}

\section{Kerusakan Ekosistem Gambut}

Kerusakan fungsi ekosistem gambut terjadi akibat dari pengelolaan lahan yang salah dengan pemilihan komoditas bisnis yang tidak sesuai dengan karakteristik lahan gambut. Hal ini diperparah dengan pengurasan air gambut yang berakibat kekeringan (kering tak balik) pada gambutnya itu sendiri yang saat ini sebagai pemicu kebakaran. Fakta dilapangan menunjukkan kebakaran yang terjadi hampir setiap tahun dengan luasan yang selalu bertambah merupakan kenyataan bahwa gambut tidak lagi dalam kondisi alaminya atau sudah mengalami kerusakan.

\section{Program Pencegahan}

- Penerapan kebijakan pemetaan terpadu kesatuan hidrologis gambut (one map policy)

- Penetapan fungsi lindung dan fungsi budidaya ekosistem gambut

- Pelaksanaan evaluasi dan audit perizinan pemanfaatan lahan gambut yang telah dikeluarkan

- Penyelamatan lahan gambut bekas kebakaran dengan pemulihan ekosistem gambut

- Peningkatan kapasitas pengendalian dan pengawasan pemanfaatan lahan ekosistem gambut 


\section{Langkah Pencegahan}

- Peningkatan Kapasitas Masyarakat

- Penataan ulang pemanfaatan ekosistem gambut:

- Tidak ada pembukaan lahan baru untuk eksploitasi lahan gambut.

- Zonasi kawasan lindung dan kawasan budidaya.

- Tata kelola air melalui pendekatan ekohidro.

- Penataan ulang Rencana Kerja Usaha (RKU) dan Rencana Kerja Tahunan (RKT) untuk dunia usaha.

- Pengamanan areal kerja untuk mengurangi resiko kebakaran bagi dunia usaha.

- Tidak ada izin baru.

Gambar 2 berikut merupakan contoh zonasi kawasan lindung dan kawasan budidaya di lahan gambut.

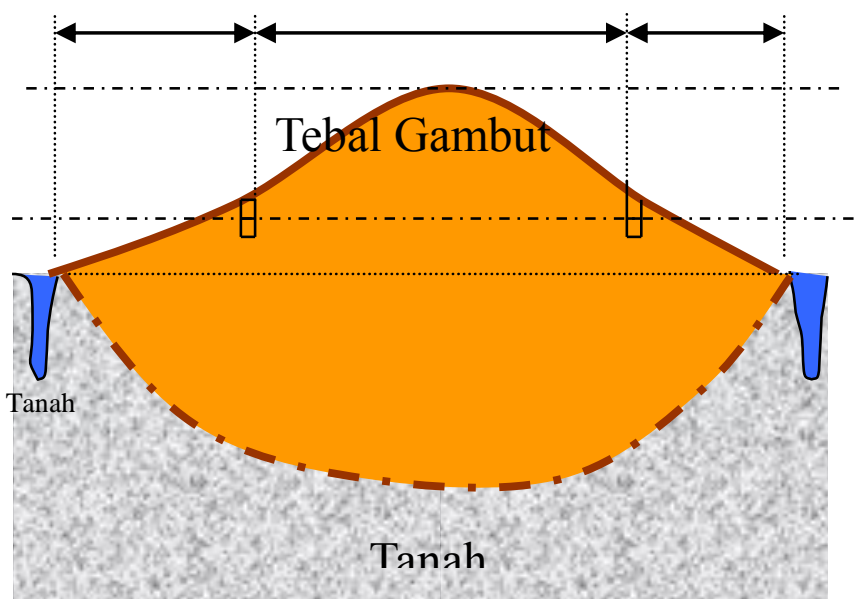

Gambar 2. Zonasi kawasan lindung dan kawasan budidaya di lahan gambut

\section{Pemulihan Ekosistem Gambut}

- Suksesi alami

- Rehabilitasi ekosistem

- Restorasi ekosistem

- Cara lain sesuai pengetahuan dan teknologi

\section{Rehabilitasi Ekosistem}

- Revegetasi (penanaman kembali) :

- tanaman buah, tanaman pangan

- Hasil Hutan Bukan Kayu (getah, rotan, lebah madu)

- Tanaman yang menghasilkan kayu energi,
- Tanaman kayu alternatif sumber serat misalnya gerunggang (Cratoxylon arborescens)

- Silvikultur

- Agroforestry

- Pengkayaan vegetasi untuk suksesi

- Rewetting (pembasahan kembali) dengan kanal blocking atau teknologi lain untuk menahan air pada saat-saat tertentu (diawali dengan rappid assessment)

- Membuat embung di kawasan rawan kebakaran

\section{Restorasi Ekosistem}

- Restorasi terutama dilakukan pada kubah yang mempunyai fungsi lindung,

- Dilakukan pengaturan tata kelola air :

- Tidak membangun saluran air yang baru

- Penataan kembali saluran/kanal buatan dengan pembuatan/pemasangan sekat kanal, (dapat di kombinasikan dengan vegetasi)

- Penanaman dengan jenis-jenis tanaman endemik atau spesifik lokasi. (untuk yang sudah terlanjur di tanam dengan jenis tanaman lahan kering, ditunggu sampai siklus panen).

Arah kebijakan kawasan pengelolaan adaptif di lahan gambut dapat dilihat pada Gambar 3.

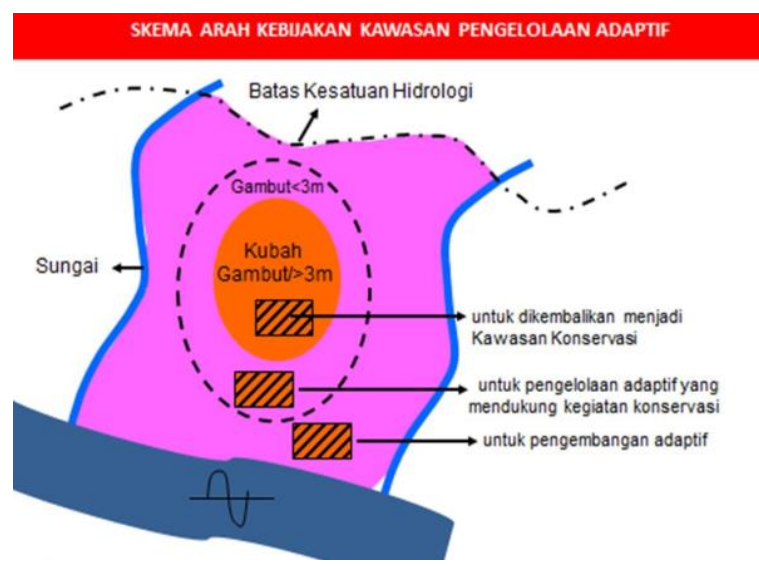

Gambar 3. Skema arah kebijakan kawasan pengelolaan adaptif 
Hal Penting dalam Pengelolaan Ekosistem

Gambut

\section{Pencegahan}

- Penguatan sistem peringatan dini,

- Penerapan petunjuk teknis operasional Audit kepatuhan

- Sosialisasi bahaya kebakarann dan sanksi

- Pemberdayaan dan peningkatan ekonomi masyarakat

- Penerapan perangkat dan teknologi pembukaan lahan tanpa bakar

- Konsolidasi kelembagaan

- Pemantauan titik hotspot

- Kebijakan insentif utk penyiapan lahan tanpa bakar

- Kesiapan sarana dan prasarana

\section{Pemulihan}

- Inventarisasi pemetaan wilayah

- Resolusi konflik

- Pemulihan fisik

- Pengelolaan areal bekas

- Kebakaran yang dikembalikan kepada negara

\section{Restorasi}

- Perencanaan, mapping dan zonasi

- Konstruksi, operasional dan pemeliharaan

- Pengembangan kapasitas kelembagaan

- Sosialisasi, monitoring dan evaluasi

- Penelitian dan pengembangan

\section{Penegakan Hukum}

- Peningkatan kesadaran hukum masyarakat

- Pengamanan kawasan

- Pengawasan izin lingkungan

- Pengawasan perizinan dan audit kepatuhan

- Proses hukum acara

\section{DAFTAR PUSTAKA}

Gandasasmita, K dan B. Barus. 2012. Pengelolaan lahan gambut berkelanjutan di Indonesia.

Disampaikan pada Acara Semiloka "Strategi Nasional Pengelolaan Lahan Gambut Berkelanjutan di Indonesia, IPB ICC, Bogor, 12 Oktober 2012.

Subiksa, I. G. M. dan Wahyunto. 2011. Genesis lahan gambut di Indonesia. Pengelolaan lahan gambut berkelanjutan. Nurida, N. L., A. Mulyani dan F. Agus (ed). Balai Penelitian Tanah, Balai Besar Litbang Lahan Pertanian, Badan Penelitian dan Pengembangan Pertanian, Kementerian Pertanian.

Wahyunto, A. Hidayat, dan A. Iskandar. 2010. Karakteristik lahan gambut di lokasi demplot ICCTF Provinsi Riau, Jambi, Kalimantan Tengah dan Kalimantan Selatan. Balai Besar Litbang Sumberdaya Lahan Pertanian, Bogor.

Yuwono, N. W. 2009. Membangun kesuburan tanah di lahan marginal. Jurnal Ilmu Tanah dan Lingkungan Vol. 9 No. 2 (2009) p: 137-141. 